\title{
PERANCANGAN SISTEM INFORMASI AKADEMIK PADA PAUD GODWILLING MAMPANG DEPOK BERBASIS JAVA MENGGUNAKAN METODE R\&D
}

\author{
Zaki Rahmani ${ }^{1}$, Naely Farkhatin ${ }^{2}$, Retna Ningsih ${ }^{3}$ \\ 1,2,3 Universitas Indraprasta PGRI \\ Jl. Raya Tengah No.80, RT.6/RW.1, Gedong, Kec. Ps. Rebo, Kota Jakarta Timur, DKI Jakarta 13760 \\ 1rahmanizaki99@gmail.com, 2‥naely_farkhatin@yahoo.com, ${ }^{3}$ ennatatto@gmail.com
}

\begin{abstract}
ABSTRAK
Paud Godwilling sampai dengan saat ini belum sepenuhnya menggunakan pengolahan data secara komputerisasi dan menggunakan aplikasi, pengolahan data masih dilakukan secara manual kurang teroganisasi dengan baik sehingga data-data yang dikelola menjadi kurang konsisten, kurang lengkap dan tidak akurat serta belum efisien dan efektif. Tujuan penelitian untuk menggantikan sistem akademik pada Paud Godwilling yang masih manual menjadi sistem yang terkomputerisasi. Metode penelitian yang digunakan pada penelitian ini adalah Research and Development $(R \& D)$. Metode penelitian ini digunakan untuk menghasilkan produk tertentu dan menguji keefektifan produk tersebut, Produk yang dihasilkan berupa aplikasi akademik berbasis java pada Paud Godwilling dapat membantu pihak tata usaha menjadi lebih efektif dan efisien dalam bentuk biaya dan waktu dalam pengolahan data pendaftaran, siswa dan guru, penjadwalan bagi guru dan proses pembuatan laporan.
\end{abstract}

Kata Kunci: Aplikasi, Akademik, Sistem Informasi, Java

\begin{abstract}
Paud Godwilling until now has not fully used computerized data processing and uses applications, data processing is still done manually less well-so that managed data becomes inconsistent, incomplete and accurate is not and not efficient and effective. The purpose of the study was to replace the academic system in Paud Godwillinhg which was still manual into a computerized system. The research method used in this research is Research and Development $(R \& D)$. This research method is used to produce a particular product and test the effectiveness of the product, the resulting product in the form of java-based academic applications on Paud Godwillinh can help businesses become more effective and efficient in the form of cost and time in processing registration data, students and teachers, scheduling for teachers and the process of making reports.
\end{abstract} Key Word: Application, Academic, Information Systems, Java

\section{PENDAHULUAN}

Sistem data serta teknologi komputer berkembang pesat sejalan dengan besarnya kebutuhan terhadap data. Perkembangan teknologi informasi tidak terlepas dari pesatnya kemajuan teknologi komputer, karena komputer merupakan media yang dapat memberikan kemudahan bagi manusia dalam menyelesaikan suatu pekerjaan. Transformasi publik yang semakin cepat bersamaan dengan pertumbuhan jaman serta teknologi sehingga membutuhkan mutu data yang akurat, cepat serta pas.

Paud Godwilling Depok adalah lembaga pendidikan anak di jalur non-formal didirikan pada tahun 2012 yang diselenggarakan oleh bapak M. Soleh AZ dan dikelola oleh Ibu indah Susilowati, S.PD. Paud Godwilling saat ini belum sepenuhnya menggunakan sistem terkomputerisasi, sistem pengolahan data masih dilakukan secara manual sehingga data yang dikelola tidak teroganisir dengan baik, tidak efesien dan efektif.

Sekolah sebagai suatu instansi dibidang pendidikan yang memerlukan sistem informasi dalam operasionalnya, seperti proses kegiatan belajar mengajar dan proses akademik. menjadi lebih efisien dengan tersedianya sistem yang terkomputerisasi, sehingga akan memberikan hal positif dan manfaat untuk perkembangan sekolah. Pengolahan data siswa, data guru, dan data jadwal mengajar yang dilakukan secara manual menyebabkan beberapa kendala dibidang akademik seperti kurang akurat dalam pengolahannya, data siswa, data guru, dan data jadwal mengajar tidak tersimpan dengan baik dan sering terjadi kesalahan saat

454 | Perancangan Sistem Informasi Akademik pada Paud Godwilling Mampang Depok Berbasis Java Menggunakan Metode R\&D 
proses pengolahan data siswa, data guru, dan data jadwal mengajar sehingga mempengaruhi laporan data yang akan di diberikan kepada kepala sekolah Paud Godwilling.

Bersumber pada permasalahan tersebut, diperlukan suatu sistem yang bisa menuntaskan bermacam permasalahan yang ada agar sanggup terorganisasi dengan baik. Sebuah sistem akan mampu membantu dalam pengolahan data siswa, data guru, dan data jadwal mengajar. Dengan permasalahan tersebut peneliti tertarik untuk melakukan penelitian di Paud Godwilling dalam bidang akademik sekolah dengan judul "Perancangan Sistem Informasi Akademik Pada Paud Godwilling Mampang Depok Berbasis Java”. Perancangan sistem adalah sebuah proses yang menentukan bagaimana suatu sistem akan menyelesaikan apa yang mesti diselesaikan.(Darmawan et al., 2013). Sistem adalah suatu jaringan kerja dari prosedurprosedur yang saling berhubungan, berkumpul bersama-sama untuk melakukan kegiatan atau sasaran yang tertentu, Informasi adalah data yang diolah menjadi bentuk yang lebih berguna dan lebih berarti bagi penerimanya.(Hutahaean, 2014).

Akademik dalam konteks Sekolah, dilampirkan dengan segala hal yang berkaitan dengan penguasaan ilmu pengetahuan yang perlu dikuasai oleh pelajar setelah mengikuti proses pembelajaran, sehingga yang disebut dengan aktiviti proses pembelajaran dal hal-hal lain yang berkaitan dengan itu misalnya menyusun jadwal akademik pembelajaran.(Pauzi, 2019). Adapun tujuan dalam penelitian ini adalah untuk memberikan gambaran secara umum kepada masyarakat tentang aplikasi akademik dan dapat berguna bagi pihak-pihak yang memerlukan referensi maupun sebagai bahan pembanding.

Penulis membuat aplikasi sistem informasi ini menggunakan bahasa pemrograman Java dengan editor Netbeans. "Bahasa pemrograman ini merupakan pengembangan dari bahasa pemrograman $\mathrm{C}++$ karena banyak mengadopsi sintak $\mathrm{C}$ dan $\mathrm{C}++$. Saat ini Java merupakan bahasa pemrograman yang paling populer digunakan, dan secara luas dimanfaatkan dalam pengembangan berbagai jenis perangkat lunak aplikasi atau pun aplikasi berbasis web".(Nofriadi, 2018). Netbeans adalah sebuah software Integrated Development Environment (IDE) yang berbasis Java dari Sun Microsystems yang berjalan di atas swing dan banyak digunakan sebagai editor untuk berbagai bahasa pemrograman (Nofriadi, 2018). Media penyimpanan data pada aplikasi ini memakai database MySQL. "Database adalah suatu aplikasi yang menyimpan sekumpulan data. Setiap database mempunyai API tertentu untuk membuat, mengakses, mengatur, mencari, dan menyalin data yang ada di dalamnya".(Jubilee Enterprise, 2014). "MySOL adalah RDBMS yang cepat dan mudah digunakan, serta sudah banyak digunakan untuk berbagai kebutuhan. MySQL dikembangkan oleh MySQL AB Swedia".(Jubilee Enterprise, 2014)

Berbanding dengan metode penelitian dan perancangan sistem pada penelitian yang relevan barjudul "Perancangan Sistem Informmasi Akademik menggunakan Java dan Mysql pada SMP Sumbangsih Jakarta. (Mohamad Bilal, 2013). Yang menggunakan metode penelitian dengan Grounded Research sehingga proses penelitian membutuhkan waktu yang lebih lama.

\section{METODE PENELITIAN}

Penelitian (research) pada hakikatnya merupakan salah satu cara untuk menyelesaikan suatu masalah atau mencari jawaban dari persoalan yang dihadapi secara ilmiah.(dr. Drs. Ismail Nurdin \& Dra. Sri Hartanti, 2019). Jenis metode penelitian yang digunakan pada penelitian ini adalah Research and Development $(R \& D)$. Research and Development $(R \& D)$ adalah metode penelitian yang menghasikan sebuah produk dalam bidang keahlian tertentu, yang diikuti produk sampingan tertentu serta memiliki efektifitas dari sebuah produk tersebut, produk tersebut berupa perangkat keras atau perangkat lunak.(Budiyono Saputro, 2017).

Model pada penelitian ini adalah model prosedural, Model ini merupakan model penelitian yang menekankan pada keberaturan pada prosesnya. (Yudi Hari Rayanto \& 
Sugianti, 2020). Langkah-langkah yang bisa diikuti untuk menghasilkan suatu produk meliputi tahap potensi dan masalah, pengumpulan data, desain produk, validasi desain, revisi desain produk, uji coba produk, revisi produk, uji coba pemakaian, revisi produk, dan produksi masal.

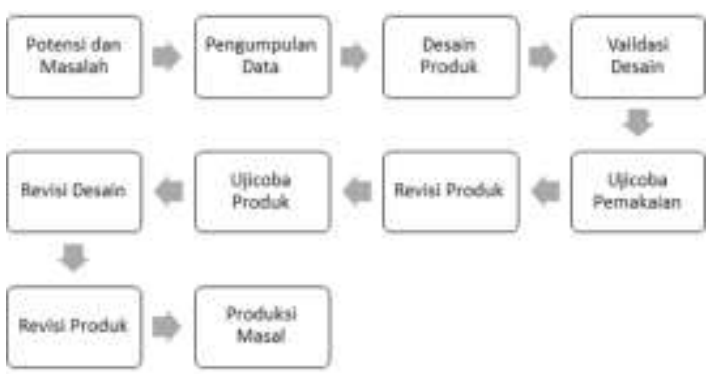

Gambar 1. Design Alur Penelitian

Metode pengumpulan data yang diterapkan oleh penulis untuk mendapatkan data-data dan informasi sebagai mendukung penyempurnaan hasil dari penelitian ini, antara lain:

1. Studi Kepustakaan (Library research)

Riset pustaka sekaligus memanfaatkan sumber perpustakaan untuk memperoleh data penelitiannya.(Mestika Zed, 2004). Pengumpulan data dan informasi dilakukan diperpustakaan Universitas, kutipan kutipan buku dan browsing melalui search engine di internet.

2. Studi Lapangan (Field Research)

a. Observasi adalah cara pengumpulan data dengan mengadakan pengamatan langsung terhadap suatu objek dalam suatu periode tertentu dan mengadakan pencatatan secara sistematis tentang hal-hal tertentu yang diamati.

b. Wawancara adalah teknik pengumpulan informasi yang dilakukan dengan cara tanya jawab antara penanya (interviewer) dengan penjawab (responden)

\section{Diagram Konteks}

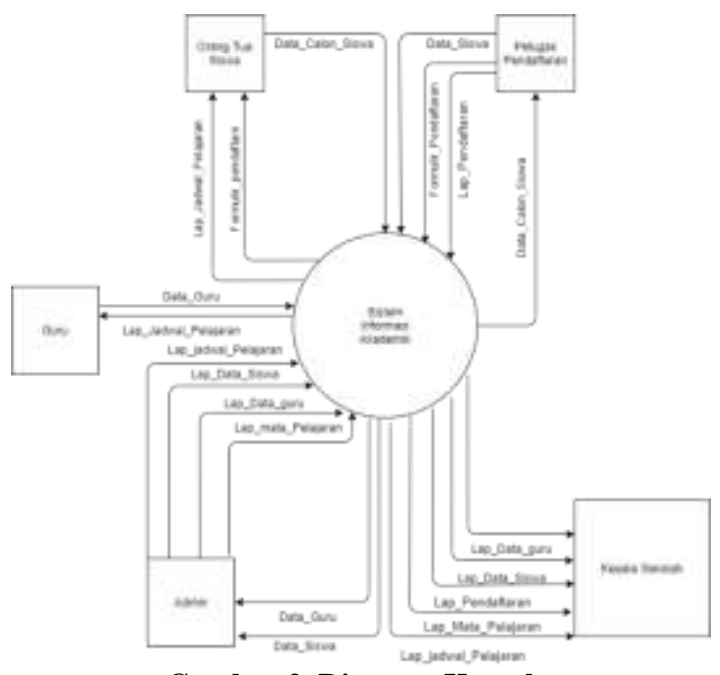

Gambar 2. Diagram Konteks

Gambar 2 merupakan gambaran sistem yang diusulkan oleh penulis untuk Paud Godwilling. Alur data diawali dengan penginputan data oleh petugas pendaftaran dengan masukan formulir pendaftaran, orang tua murid menginput data calon siswa yang mana data tersebut akan diinput oleh petugas pendaftaran sebagai data siswa, lalu data tersebut diterima oleh admin beserta data guru yang sudah diinput oleh guru, admin membuat data jadwal pelajaran dan data mata pelajaran, kemudian data data tersebut akan diolah dan diinput menjadi laporan yang akan diberikan kepada kepala sekolah.

\section{ERD (Entity Relationship Diagram)}

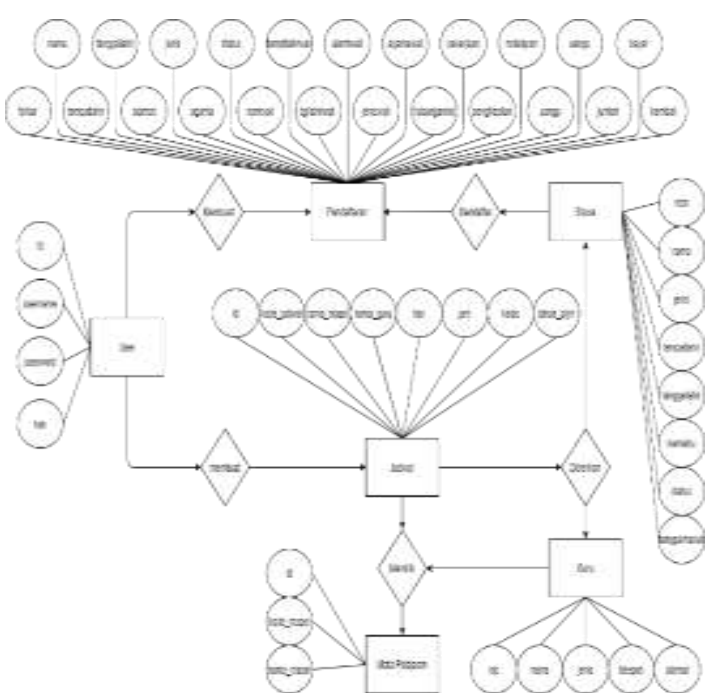

Gambar 3. ERD (Entity Relationship Diagram)

\section{HASIL DAN PEMBAHASAN}

456 | Perancangan Sistem Informasi Akademik pada Paud Godwilling Mampang Depok Berbasis Java Menggunakan Metode R\&D 


\section{Normalisasi 1NF}

\begin{tabular}{|c|c|c|}
\hline user & siswa & pendaftaran \\
\hline $\begin{array}{l}\text { id } \\
\text { username } \\
\text { password } \\
\text { hak }\end{array}$ & \multirow{2}{*}{\begin{tabular}{|l} 
nisn \\
nama \\
jenis \\
tempatlahir \\
tanggallahir \\
namaibu \\
status \\
tanggalmasuk \\
\end{tabular}} & \multirow{6}{*}{\begin{tabular}{|l} 
faktur \\
nama \\
tempatlahir \\
tanggallahir \\
alamat \\
jenis \\
agama \\
status \\
namawali \\
tempatlahirwali \\
tanggallahirwali \\
alamatwali \\
jeniswali \\
agamawali \\
hubungankeluarga \\
pekerjaan \\
penghasilan \\
notelepon \\
uangp \\
uangs \\
jumlah \\
bayar \\
kembali
\end{tabular}} \\
\hline jadwal & & \\
\hline \multirow{4}{*}{$\begin{array}{l}\text { id } \\
\text { kode_jadwal } \\
\text { nama_mapel } \\
\text { nama_guru } \\
\text { hari } \\
\text { jam } \\
\text { kelas } \\
\text { tahun_ajaran }\end{array}$} & mapel & \\
\hline & $\begin{array}{l}\text { id } \\
\text { kode_mapel } \\
\text { nama_mapel }\end{array}$ & \\
\hline & guru & \\
\hline & \begin{tabular}{|l} 
nip \\
nama \\
jenis \\
telepon \\
alamat \\
\end{tabular} & \\
\hline
\end{tabular}

Gambar 4. Normalisasi 1NF

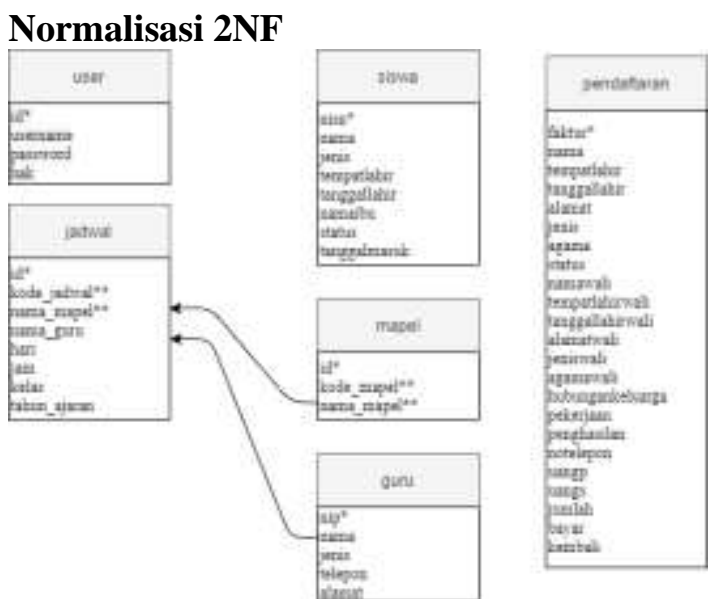

Gambar 5. Normalisasi 2NF

\section{Tampilan Layar Tampilan Menu Utama}

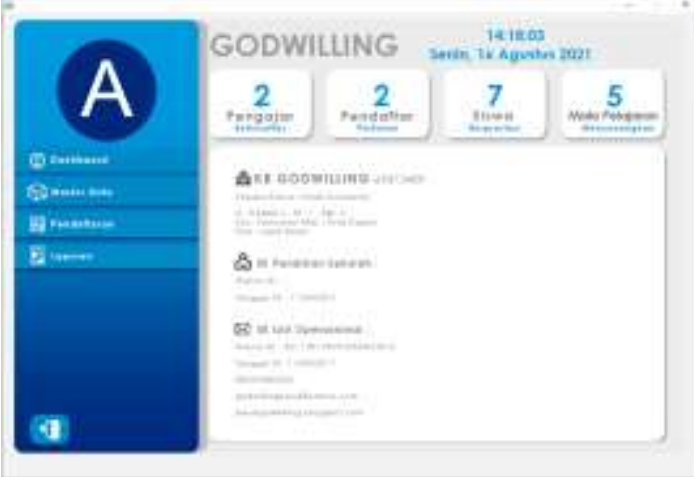

Gambar 6. Tampilan Menu Utama

Dalam tampilan menu utama terdapat informasi paud dan menu master data, menu pendaftaran, menu laporan.
Tampilan Laporan Guru

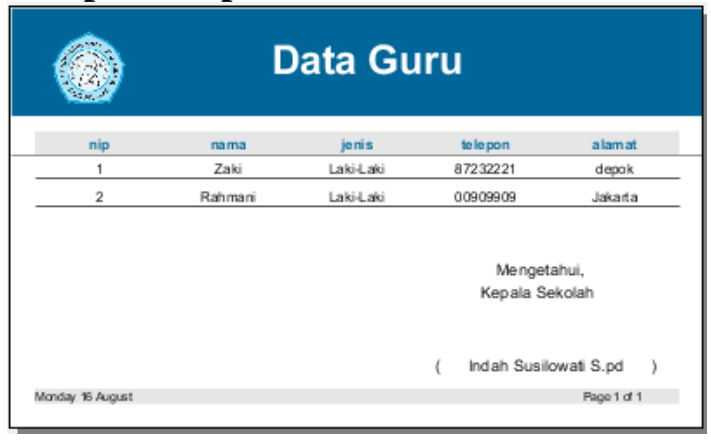

Gambar 7. Tampilan Laporan Guru

Berdasarkan gambar 7, adalah hasil dari form data guru yang diinput dan menghasilkan laporan data gur yang terdiri dari nip, nama siswa, jenis kelamin, telepon, dan alamat.

\section{Hasil Pengujian}

Pengujian blackbox dilakukan dengan menguji perangkat lunak dari segi fungsional software tersebut. Berikut adalah hasil pengujian dengan metode blackbox dalam aplikasi sistem informasi akademik Paud Godwilling.

Tabel 1. Hasil Pengujian BlackBox

\begin{tabular}{|c|c|c|}
\hline Aksi Aktor & Reaksi Sistem & Hasil pengujian \\
\hline \multicolumn{3}{|c|}{ Alur Dasar } \\
\hline $\begin{array}{c}\text { Data } \\
\text { Pendaftaran }\end{array}$ & $\begin{array}{l}\text { Dalam form pendaftaran sudah } \\
\text { bisa dijalankan karna sudah } \\
\text { tidak ada permintaan dari user. }\end{array}$ & Sesuai \\
\hline Data Guru & $\begin{array}{l}\text { bisa dijalankan karna sudah } \\
\text { tidak ada permintaan tambahan } \\
\text { dari user. }\end{array}$ & Sesuai \\
\hline Data Siswa & $\begin{array}{l}\text { Diform data siswa sudah bisa } \\
\text { dijalankan oleh pihak user, } \\
\text { karna sudah sesuai dengan } \\
\text { permintaan user. }\end{array}$ & Sesuai \\
\hline $\begin{array}{l}\text { Data Mata } \\
\text { Pelajaran }\end{array}$ & $\begin{array}{l}\text { Dalam form data mata } \\
\text { pelajaran sudah bisa dijalankan } \\
\text { karna sudah tidak ada } \\
\text { permintaan tambahan dari user. }\end{array}$ & Sesuai \\
\hline $\begin{array}{c}\text { Data Jadwal } \\
\text { Pelajaran }\end{array}$ & $\begin{array}{l}\text { Dalam form data jadwal } \\
\text { pelajaran sudah bisa dijalankan } \\
\text { karna sudah tidak ada } \\
\text { permintaan tambahan dari user. }\end{array}$ & Sesuai \\
\hline
\end{tabular}

Hasil dari pengujian blacbox ini adalah aplikasi sistem informasi ini sudah berjalan sesuai dengan fungsinya dan bisa digunakan. Karena tidak adanya permintaan tambahan oleh pihak sekolah, maka aplikasi yang dibuat telah sesuai dengan spesifikasi yang diharapkan. 


\section{SIMPULAN DAN SARAN}

Berdasarkan rincian hasil penelitian, Aplikasi Informasi Akademik ini berjalan sesuai harapan, dan masalah-masalah yang dijabarkan pada rumusan masalah dapat diselesaikan. Dengan adanya Aplikasi Informasi Akademik ini, admin disini bisa lebih mudah dalam pengolahan dan pencatatan laporan data guru dan murid yang masuk pada paud ini, admin juga dapat menggunakan fitur-fitur yang terdapat pada aplikasi ini, diantaranya:

Pembuatan aplikasi sistem informasi Paud Godwilling ini membantu proses pendataan murid, guru, jadwal pembelajaran pada sekolah. Fitur pendataan murid, guru, dan jadwal pelajaran bias membantu sekolah sehingga mempermudah dan mempercepat proses untuk melakukan pengarsipan data sekolah

Dengan adanya form-form beserta laporan dalam aplikasi ini, kepala sekolah bisa mengetahui dan mengontrol pendataan dan penjadwalan sekolah.

Untuk kedepannya, diharapkan aplikasi ini dapat dikembangkan dengan fasilitas-fasilitas lainya untuk memudahkan admin dan sekolah, sert rutin mengupdate tampilan aplikasi ini menjadi lebih menarik agar tidak bosan dalam menggunakan aplikasi ini.

\section{UCAPAN TERIMAKASIH}

Saya ucapkan rasa syukur kepada Allah SWT dan terimakasih kepada semua pihak yang membantu dalam menyusun jurnal, terutama kepada orang tua, dosen pembimbing, kaprodi, dan teman teman ku sekalian.

\section{DAFTAR PUSTAKA}

Budiyono Saputro. (2017). Manajemen PENELITIAN PENGEMBANGAN (Research \& Development). Aswaja Presindo.

Darmawan, Deni, \& Fauzi Nur. (2013). Sistem Informasi Manajemen. PT. Remaja Rosadakarya.

dr. Drs. Ismail Nurdin, M. S., \& Dra. Sri Hartanti, M. S. (2019). Metodologi penelitian sosial. penerbit media sahabat.

Hutahaean, J. (2014). Konsep Sistem
Informasi. deepublish.

Jubilee Enterprise. (2014). MySQL untuk Pemula. PT Elex Media Komputindo.

Mestika Zed. (2004). Metode Penelitian Kepustakaan. yayasan Obor Indonesia.

Mohamad Bilal. (2013). Perancangan Sistem Informmasi Akademik menggunakan Java dan Mysql pada SMP Sumbangsih. Indraprasta PGRI (UNINDRA).

Nofriadi, M. K. (2018). JAVA Fundamental dengan Netbeans 8.0.2. deepublish.

Pauzi, P. . (2019). Model Pengawasan Sekolah yang Berkesan. PT. Indragiri.

Yudi Hari Rayanto, \& Sugianti. (2020). Penelitian Pengembangan Model Addie dan R2D2. Lembaga Academic \& Reseatch Institute. 